\title{
GÊNERO E SEXUALIDADE EM POLÍTICAS CONTEMPORÂNEAS: ENTRELACES COMA EDUCAÇÃO
}

\section{GENDER AND SEXUALITYIN CONTEMPORARY POLICIES: INTERLINKS WITH EDUCATION}

\section{GÉNERO Y SEXUALIDAD EN LAS POLÍTICAS CONTEMPORÁNEAS: ARTICULACIONES CON EL CAMPO DE LA EDUCACIÓN}

\author{
Bianca Salazar Guizzo* \\ Professora Adjunta e Pesquisadora da Universidade Luterana do Brasil \\ Jane Felipe ${ }^{* *}$ \\ Professora Associada IV da Universidade Federal do Rio Grande do Sul
}

\begin{abstract}
Resumo: A partir das contribuições dos Estudos de Gênero e dos Estudos Culturais, os propósitos principais deste trabalho são: 1) apresentar algumas políticas públicas que mencionam as questões de gênero e sexualidade; 2) discutir aspectos que têm dificultado a inserção dessas questões nas escolas. Os resultados apontaram que tem havido um incremento de documentos que dão visibilidade às questões de gênero e sexualidade. Porém, alguns deles não chegam a ser postos em prática, em virtude da resistência de setores conservadores. Apesar disso, tem ocorrido um esforço para contemplar tais questões no currículo, embora ainda sejam apontadas algumas dificuldades que se vinculam à falta de formação docente e à resistência das famílias em permitir o trabalho com tais temáticas.
\end{abstract}

Palavras-chave: Políticas Públicas. Gênero. Sexualidade. Educação.

Abstract:Based onthe contributions of Gender Studies and Cultural Studies, the main purposes of this work are: 1) to present some public policies that mention gender and sexuality issues; 2) to discuss aspects that have hindered the inclusion of these issues in schools. The results showed that there has been an increase of documents that make

\footnotetext{
* Doutora em Educação pela Universidade Federal do Rio Grande do Sul; Mestre em Educação pela Universidade Federal do Rio Grande do Sul.

** Doutora em Educação pela Universidade Federal do Rio Grande; Mestre em Educação pela Universidade Federal Fluminense.
} 
gender and sexuality visible. However, some of them fail to be implemented, due to resistance of conservative groups. Nevertheless, there has been an effort to contemplate these issues in the curriculum, in spite of difficulties linked to the lack of teacher training as well as to family resistance to pedagogical work with such issues.

Keywords: Public Policies. Gender. Sexuality. Education.

Resumen: A partir de las contribuciones de los Estudios de Género y de los Estudios Culturales, los principales objetivos de este trabajo son: 1) presentar algunas políticas públicas que mencionan las cuestiones de género y la sexualidad;2) examinar las cuestiones que han impedido la inclusión de estos temas en las escuelas. Los resultados mostraron que ha habido un aumento de documentos que dan visibilidad a las cuestiones de género y sexualidad. Pero algunos de ellos no llegan a ser usados y trabajados en las escuelas, debido a la resistencia de los sectores conservadores. Ha habido un esfuerzo por contemplar estas cuestiones en los planes de estudios. Sin embargo se identifican algunas dificultades que están vinculados a la falta de formación del profesorado y la resistencia de las familias para permitir el trabajo con las cuestiones de género y sexualidad.

Palabras-clave: Politicas Públicas. Género. Sexualidad. Educación.

\section{CONSIDERAÇÕES INICIAIS}

O objetivo deste trabalho é analisarparte dos resultados de pesquisas que temos desenvolvido nos últimos anos sobre aspolíticas públicas contemporâneas que contemplam as temáticas de gênero e sexualidade. Tomando como referenciais os Estudos de Gênero e os Estudos Culturais de viés pós-estruturalista, neste artigo, especificamente, a problematização atrelar-se-á a dois propósitos principais: 1) apresentar algumas políticas públicas que mencionam as questões de gênero e sexualidade;2) discutir alguns aspectos que têm dificultado a efetiva inserção dessas questões nas escolas contemporâneas. No entanto, antes de empreender tal problematização, será feita uma retomada a respeito da importância que a questão das diferenças começou a ganhar no âmbito educacional brasileiro, principalmente no que diz respeito a gênero e sexualidade.

Especialmente a partir da segunda metade do século XX, a forma como a educação vinha sendo proposta passou a ser alvo de contestações. Na pauta dessas discussões estavam as reivindicações de grupos que, por longo tempo, estiveram à margem da sociedade. Tais segmentos, a saber: indígenas, pessoas com deficiência, ne- 
gros/as, mulheres e não heterossexuais passaram a reivindicar seus direitos, ganhando assim força política e representacional. Em suas construções identitárias, pleiteavam que suas diferentes formas de ser, pensar, pertencer e viver fossem respeitadas.

Movimentos que se atrelavam a esses grupos, aos poucos, começaram, a ganhar força e importância. Ou seja, especialmente a partir da segunda metade da década de 1960 a política de identidades começou a adquirir mais visibilidade entre grupos que buscavam o direito de ter suas diferenças reconhecidas: não como o exótico, o estranho, e sim como uma forma de vida que é a sua.

Importante destacar que, a partir da perspectiva teórica adotada, as diferenças não são marcas naturais dos seres humanos, elas são - ao mesmo tempo - produto e efeito de certas maneiras de representá-las, ou seja, são decorrentes da linguagem, que tem a capacidade de fazer classificações, ordenamentos, diferenciações que acabam estabelecendo quem são os sujeitos desejáveis e "normais". O entendimento de gênero, por exemplo, não se vincula estritamente a algo natural e biológico. Ao contrário, ele se liga também a aspectos sociais e culturais. Dito de outro modo: não se nasce homem ou mulher,mas são feitos inúmeros investimentos com o intuito de ensinar atributos e legados que, cultural e socialmente, se vinculam ao masculino e ao feminino (BECK; GUIZZO, 2013).

Rodrigues e Abramowicz (2013) salientam que a temática das diferenças e outros temas a ela relacionados têm sido tratados de forma central no debate nacional e internacional, com o intuito de desenvolver e formular políticas públicas especialmente na área da educação, já que aí é possível produzir, conciliar e/ou responder aos conflitos que estão colocados na sociedade.

No Brasil, a década de 1990 foi marcada por um contexto reivindicatório,no qual diferentes movimentos sociais denunciaram as práticas discriminatórias presentes na educação e exigiram mudanças. O Ministério da Educação tem promovido iniciativas, debates e discussões com o propósito de superar os preconceitos e as discriminações em instituições escolares em razão de especificidades que marcam os sujeitos como "diferentes". Estas discussões, bem como outras ações de movimentos sociais, contribuíram para a elaboração de documentos oficiais que teriam emergido com o propósito de proporcionar uma educação similar para todos e todas, independente de gênero, raça, sexualidade, classe social e outros marcadores possíveis. Tais documentos serão foco de análise no tópico a seguir. 


\section{GÊNERO E SEXUALIDADE EM POLÍTICAS CONTEMPORÂNEAS}

Por séculos, homens e mulheres foram diferenciados por disputas de poder, utilizando-se, para isso, argumentos relacionados às suas possíveis "essências", principalmente observando aspectos biológicos. Porém, graças a novas perspectivas teóricas, que pretendem "abalar certezas", como os Estudos Culturais, os Estudos de Gênero, os Estudos Gays e Lésbicos e a Teoria Queer, tem sido possível procurar novos caminhos para tratar de temas tão recorrentes e importantes, em especial no campo da educação. Louro (2009) argumenta que gênero foi um conceito desenvolvido para contestar a naturalização das diferenças sexuais em diversos espaços de disputa, além do que ele não se restringe apenas aos papéis assumidos por homens e mulheres na sociedade, mas diz respeito às relações de poder que estão implicadas entre masculino e feminino. O conceito de sexualidade, por sua vez, vincula-se à forma como os sujeitos expressam seus desejos e prazeres na relação com os outros e/ou com seus próprios corpos.

Felipe (2007,p. 78) destaca a visibilidade que não só o conceito de gênero, mas também o de sexualidade têm adquirido desde a década de 1970, "no meio acadêmico, bem como nos movimentos sociais, nas organizações não governamentais, na militância político-partidária, nas políticas públicas." De acordo com a autora, muitas iniciativas têm sido implementadas com o objetivo de promover a equidade de gênero e de garantir os direitos sexuais de todos os sujeitos. No Brasil, tanto as questões de gênero quanto as de sexualidade têm ganhado destaque em diversas instâncias. Tal destaque está atravessado pelo viés dos Direitos Humanos que se fundamentam no reconhecimento e no respeito às diferenças e às particularidades de cada sujeito ou grupo de sujeitos.

Em termos legais, a Constituição Federal de 1988 não pode deixar de ser mencionada, pois em seu Artigo $3^{\circ}$, entre os objetivos fundamentais mencionados, está, no inciso IV, o de "promover o bem de todos, sem preconceitos de origem, raça, sexo, cor, idade e quaisquer outras formas de discriminação.” (BRASIL, 1988).

A atual Lei de Diretrizes e Bases da Educação Nacional de 1996 (Lei 9.394/1996), inicialmente, em seu Artigo 26 determinava que "Os currículos da educação infantil, do ensino fundamental e do ensino médio devem ter base nacional comum, a ser complementada, em cada sistema de ensino e em cada estabelecimento escolar, por uma parte diversificada, exigida pelas características regionais e locais da sociedade, da cultura, da economia e dos educandos.”(BRASIL, 1996). Anos mais tar- 
de, em 2003 e em 2008, tal artigo foi alterado pelas Leis 10.639 e 11.645, enfatizando a obrigatoriedade da inclusão da história afro-brasileira e indígena nos currículos oficiais em todas as áreas de ensino. Dessa forma, a ênfase recaía sobre questões étnicoraciais. Gênero e sexualidade, em contrapartida, não eram sequer mencionados.

Em 1997, os Parâmetros Curriculares Nacionais foram publicados e, embora tenham sofrido fortes críticas, constituíram-se como referência nacional para a elaboração de currículos escolares. Além disso, é possível afirmar quefoi nesse documento, relacionado diretamente com o campo da educação, que gênero e sexualidade foram mais forte e explicitamente inseridos como temas importantes a serem discutidos nas escolas. Nos seus volumes 8 e 10, cujos títulos eram, respectivamente, "Apresentação dos temas transversais e ética", "Pluralidade cultural e orientação sexual",concentraram-se aspectos relativos a esses temas, reconhecendo-os como fundamentais na constituição de identidades de crianças e jovens. No volume 10, havia dois tópicos especialmente que procuraram promover o desenvolvimento de atividades e discussões que se articulassem às questões de gênero e sexualidade, quais sejam: "Corpo: matriz da sexualidade" e "Relações de gênero".

Em 2001, outro documento importante para o campo da Educação Básica tornou-se pauta de relevantes discussões: o Plano Nacional de Educação (PNE/Lei 10.172/2001) que estabeleciaobjetivos e metasa serem alcançados tanto nas diferentes etapas da Educação Básica, quantono Ensino Superior. Nesse PNE foram trazidas relevantes informações sobre a promoção de uma sociedade menos desigual no que diz respeito a gênero e sexualidade. Entre os objetivos e metas para o Ensino Fundamental que deveriam ser alcançados estava: "manter e consolidar o programa de avaliação do livro didático criado pelo Ministério de Educação, estabelecendo entre seus critérios a adequada abordagem das questões de gênero e etnia e a eliminação de textos discriminatórios ou que reproduzam estereótipos acerca do papel da mulher, do negro ou do índio.” (BRASIL, 2001, p.20). Nos objetivos e metas para o Ensino Superior incluía-se a necessidade de se discutir nos cursos de formação de professores temas como gênero e educação sexual, articulados a noções de justiça e respeito mútuo. Entretanto, esse PNE cujo fim ocorreu em 2011, não foi efetivamente colocado em prática, ou seja, muitos de seus objetivos e metas foram parcialmente ou não foram atingidos.

Em virtude da pouca praticidade do referido PNE (Lei 10.172/2001), é que o Plano Nacional de Educação atual (PNE/ Lei 13.005/2014) foi construído de maneira mais enxuta, com o intuito de ser realmente efetivo. Assim, no atual PNE as questões de gênero e sexualidade sequer foram citadas.Esse PNE limitou-se a um objetivo genérico de combate a qualquer forma de discriminação (BRASIL, 2014). Em 
razão da não inclusão das questões de gênero e sexualidade no PNE, sugeriu-se que tais questões deveriam integrar os Planos Estaduais e Municipais, cujas apresentações e homologações deveriam ocorrer até junho de 2015. Contudo, quando muitos desses Planos chegaram nas casas legislativas para serem sancionados, acabaram sendo barrados. Houve governantes (que se vinculam principalmente a bases religiosas) que defenderam a não aparição de termos, como "identidade de gênero" e "orientação sexual" nos Planos.

Para além das políticas vinculadas mais especificamente ao campo da educação, o início do século XXI também foi marcado pela implementação de políticas públicas relacionadas a sujeitos que não tinham seus direitos fundamentais garantidos quando nos referimos às questões de gênero e sexualidade. Houve, em 2003, a criação da Secretaria de Políticas para as Mulherese a edição de três Planos Nacionais de Políticas para Mulheres, sendo o último lançado para o período 2013-2015, bem como a sanção, em 2006, e alteração, em 2012, da Lei Maria da Penha, além da criação progressiva de Delegacias Especializadas de Atendimento à Mulher em todo o país eda criação das Varas de Violência Doméstica.

No que diz respeito à implementação de políticas públicas voltadas para mulheres, é importante referir o Programa Nacional Mulheres Mil, que foi instituído em 2011 e integra o Plano Brasil Sem Miséria do Governo Federal. Dentre os objetivos desse programa estão: a) possibilitar a formação profissional e tecnológica articulada com elevação de escolaridade de mulheres em situação de baixaescolaridade; b) contribuir para a redução de desigualdades sociais e econômicas de mulheres em situação de vulneralibidade; c) defender a igualdade de gênero; d) combater a violência contra a mulher (BRASIL, 2011). Pode-se dizer que tais propósitos estão articulados com os estudos de gênero, uma vez que se voltam para a consolidação dos direitos das mulheres. Essa consolidação é possível já que o Programa busca favorecer a libertação das mulheres de situações de dependência socioeconômica e de violência doméstica, além de procurar estimular o empoderamento feminino mediante o reconhecimento de sua trajetória, por meio da busca da elevação de sua autoestima, em virtude da reintegração ao universo escolar.

Também por intermédio das ações da Secretaria de Direitos Humanos, lésbicas, gays, bissexuais, travestis e transexuais adquiriram representatividade e lutaram para terem seus direitos respeitados. Em especial, o Plano Nacional de Promoção da Cidadania e Direitos Humanos de Lésbicas, Gays, Bissexuais, Travestis, Transexuais e Transgêneros (LGBTTT), lançadoem 2009, assinalou novos rumos na promoção e defesa da cidadania desses grupos. 
Em 2004, por meio de uma iniciativa do Governo Federal, houve a criação do programa Brasil sem Homofobia (2004), cujo objetivo central era incentivar o combate à violência e à discriminação contra sujeitos cuja orientação sexual não era a heterossexual, bem como procuraram promover a cidadania homossexual. Uma das iniciativas desse programa era distribuir um conjunto de materiais que ficou conhecido como "Kit Escola Sem Homofobia”, mas essa iniciativa foi suspensa, pois sofreu duras críticas e fortes reações de setores conservadores atrelados ao Governo. As críticas e a posterior suspensão do referido Kit muito provavelmente ocorreram pelo fato de ainda vivermos em uma cultura em que a heterossexualidade é vista como a única possibilidade de os sujeitos viverem sua sexualidade.

Autoras, como Butler (2005) e Louro (2009) operam com o conceito de heteronormatividade, mostrando o quanto a sociedade trabalha com a reiteração da heterossexualidade. Desse modo, o conceito de heteronormatividadevem sendo usado para se referir a situações nas quais orientações sexuais diferentes da heterossexual são marginalizadas, ignoradas ou perseguidas por práticas sociais, crenças ou políticas. Isto faz com que haja um entendimento fortemente propagado de que os sujeitos podem se incluir exclusivamente em duas categorias distintas e complementares: masculino e feminino. Entretanto, entre essas duas categorias pode haver infinitas possibilidades de se viver tanto as identidades de gênero, quanto as sexuais.

Relevante mencionar ainda a criação da Secretaria de Educação Continuada, Alfabetização e Diversidade (Secadi) no ano de 2004, cujos principais propósitos estavam voltados para: 1) conseguir compatibilizar o conteúdo universal da educação com o conteúdo culturalista e diferencialista de ações afirmativas para grupos, regiões e recortes específicos; 2) dar conta de colocar no centro da política pública em educação o valor das diferenças, com seus conteúdos étnico-racial, geracional, de pessoas com deficiência, de gênero, de orientação sexual, regional, religioso e cultural.

Também é importante citar as Diretrizes Curriculares Nacionais Gerais para a Educação Básica (DCN/2010), que são normas obrigatórias para a Educação Básica que orientam o planejamento curricular das escolas e sistemas de ensino, fixadas pelo Conselho Nacional de Educação (CNE). AsDCN consideram a questão da autonomia da escola e incentivam as instituições a montarem seu currículo, recortando, dentro das áreas de conhecimento, os conteúdos que lhes convêm para a formação daquelas competências que estão explicitadas nas diretrizes curriculares. Desse modo, as escolas devem trabalhar de acordo com os contextos que lhes parecerem necessários, considerando o tipo de sujeitos que atendem, a região em que estão inseridas e outros aspectos locais relevantes. 
As Diretrizes recomendam a inserção da discussão das diferenças sociais, culturais, raciais, sexuais e de gênero, já que o ingresso de diferentes sujeitos oriundos de distintos grupos sociais, étnicos, raciais e sexuais vem causando não somente grande impacto nas instituições escolares, como também nos profissionais que nelas atuam. As Diretrizes Curriculares Nacionais têm salientado que é imprescindível

[...] problematizar o desenho organizacional da instituição escolar, que não tem conseguido responder às singularidades dos sujeitos que a compõem. Torna-se inadiável trazer para o debate os princípios e as práticas de um processo de inclusão social, que garanta o acesso e considere a diversidade humana, social, cultural, econômica dos grupos historicamente excluídos. (BRASIL, 2010, p.10).

Em muitos trechos do documento descreve-se que a escola precisa dar conta dos grupos historicamente excluídos, dando maior visibilidade para estes grupos, trazendo-os para os debates no campo da educação.Além disso, ao longo do documento expressões, como: diferença e identidade, relações de gênero, narrativa étnica e racial, diversidades são recorrentemente utilizadas, o quemostra a relevância que as discussões em torno da questão das diferenças têm ganhado.

\section{EDUCAÇÃO ESCOLAR, GÊNERO E SEXUALIDADE}

É inegável o espaço e a importância que as questões de gênero e sexualidade ganharam a partir do final do século XX e desse início de século XXI em leis e políticas públicas propostas e implementadas. Mas será que elas têm produzido os efeitos esperados dentro das instituições de Educação Básica?

Embora o PNE/2001, conforme citado na seção anterior, tenha posto como meta a realização de um trabalho mais efetivo acerca dessas questões em cursos superiores de formação de professores, na prática as temáticas sobre as quais se está falando acabam sendo trabalhadas de maneira episódica e pontual, muitas vezes, sem um planejamento bem pensado e discutido. Mesmo assim, enquanto professores/as e educadores/as, é muito provável que nossos posicionamentos e opiniões produzam efeitos sobre nossos alunos. Então, mesmo que não intencionalmente, várias situações com as quais nos envolvemos e colocamos em prática ensinam e dizem sobre gênero, sexualidade, diferença e educação.

E arriscamo-nos a afirmar que muitas vezes esses posicionamentos e opiniões estão indo na contramão daquilo que procuram pregar os referidos documentos, já que - em certa medida - acabam incitando o sexismo, o machismo, a homofobiae 
a misoginia. Para discutir isso, é pertinente trazer alguns exemplos que foram mencionados nas entrevistas realizadas em pesquisas que vêm sendo por desenvolvidas ${ }^{1}$ por nosso grupo.

Uma das professoras entrevistadas relatou a seguinte situação: "Tenho um aluno que tem todo o jeito de gay. Quando formamos a fila, alunos e colegas ficam rindo, cochichando, apontando para ele [...] e eu não sei o que fazer, porque não tive formação para lidar com isso.”(informação verbal). Outra delas, contou a história de um aluno cujos comportamentos e atitudes mostravam-se homofóbicos:

Roger, do $6^{\circ}$ ano, fazia "brincadeiras" que se mostravam pre-
conceituosas. Quando via Matheus dizia: "Olha lá o bichinha"
ou "Lá vem o boiola", pelo fato de Matheus sempre estar acom-
panhado das meninas da turma. Eu observava aquilo até que um
dia posicionei-me dizendo: "Roger, eu não gosto e não quero
que tu chames o colega por apelidos como esses que chamas.
Ele tem nome e é por esse nome que vais chamá-lo, certo?!"
(informação verbal).

Um dos aspectos que tem dificultado a inserção das temáticas de gênero e sexualidade foi claramente mencionado por uma das professoras através da fala: “[...] e eu não sei o que fazer, porque não tive formação para lidar com isso."Ou seja, mesmo que documentos como o PNE/2001 tenham colocado como meta a realização de um trabalho mais efetivo no que diz respeito às referidas temáticas, os cursos de formação ainda as abordam de maneira tímida e insuficiente.

Em outra escola, duas professoras relataram que junto aos/às seus/suas alunos/as do $5^{\circ}$ ano há alguns anos vêm desenvolvendo um projeto a respeito das questões de gênero e sexualidade. Uma das atividades que faz parte do projeto é bastante conhecida da maioria dos professores e professoras que atuam na educação básica e desenvolve-se da seguinte maneira: depois de serem explorados alguns assuntos que fazem parte do projeto, uma caixinha é colocada na sala de aula para que os alunos depositem suas dúvidas e perguntas a respeito do que foi trabalhado. A identificação do que é aí depositado fica restrita às professoras. A culminância dessa atividade acontece quando um profissional que não faz parte da escola vai até lá para conversar sobre o conteúdo da caixinha.

Diferentemente de anos anteriores, em que geralmente esse profissional era vinculado à área da saúde e ia até a escola para conversar com alunos e alunas, uma de nós foiconvidada a fazê-lo. O convite foi aceito e antes do encontro presencial com as turmas do $5^{\circ}$ ano, recebemos as perguntas para planejar o conteúdo da conversa. Dentre essas perguntas, destacamos as seguintes: Por que a mulher fica menstruada? 
O que é espermatozoide? O que é fecundação? O que é progesterona? O que é púbis? O que é ejaculação? O que é "afogar o ganso"? Pode uma mulher engravidar na primeira vez? A menstruação tem cheiro? Como podemos saber quando nosso corpo se move durante a transa? Qual a idade que meninas ficam menstruadas? É normal que a primeira ejaculação ocorra durante o sono? O que acontece quando um bebê nasce prematuro? O que é relação sexual? Quais são as piores doenças sexualmente transmissíveis?

De acordo com as professoras, os assuntos que permeavam tais perguntas já haviam sido trabalhados por elas junto com as turmas. Partindo dessa colocação, percebe-se que as formas de viver/explorar o corpo e a sexualidade trabalhadas dentro da escola ainda continuam ligadas a questões biológicas e de saúde. De modo geral, professores e professoras tendem a apoiar-se nessas abordagens mais "científicas" que, de certa forma, restringem a questão da sexualidade à reprodução. Em consequência disso, há a reiteração de que há uma única forma sadia e normal de se viver a sexualidade: a heterossexual (LOURO, 2009). Àmedida que aquilo que a escola propõe liga-se, mesmo que involuntariamente, apenas a essas abordagens em que a heterossexualidade (já que esta possibilita a reprodução biológica) é colocada no centro, outras maneiras de vivê-la acabam sendo negadas e postas à margem.

De qualquer forma, a existência de algumas perguntas pouco ou nada relacionadas aos discursos biológicos e biomédicos, como: O que é afogar o ganso? Como podemos saber quando nosso corpo se move durante a transa?constituem-seexemplos de como o discurso do senso comum resiste, ignora e, da mesma forma, tensiona as supostas "verdades" científicas ensinadas na escola.

Importante destacar também que durante a conversa outras questões, além das colocadas na caixinha, foram feitas. Um dos aspectos trabalhados ao longo da conversa relacionou-se ao fato de que a sexualidade não se vincula apenas à prevenção de gravidez e doenças. Procuramos mencionar que ela pode ser, por meio de nossos corpos, fonte de desejo, prazer e satisfação e não apenas de reprodução (WEEKS, 1999). Uma vez que a sexualidade não se restringe à reprodução, foi exposto aos alunos que ela pode ser vivida de variadas formas: com o próprio corpo e/ou com o corpo do outro (sendo do sexo oposto ou não).

A partir dessa colocação, alunos e alunas sentiram-se encorajados a fazer questionamentos e comentários a respeito de conhecidos/as, familiares, personalidades e amigos/as cuja orientação sexual era homossexual: "dois homens podem se casar?", "eu tenho duas vizinhas que são casadas", "na novela tem dois homens que são casados e querem ter filho", "meu tio tem um namorado [...] minha mãe diz que 
foi o jeito que ele encontrou de ser feliz". (informações verbais). Essas são perguntas e falas que possivelmente não surgiriam caso a abordagem da conversa fosse meramente vinculada à biologia e à saúde.

Ao final da conversa, as professoras comentaram que a atividade durou além do previsto (quase duas horas), pois alunose alunas perguntaram bastante e realmente mostraram-se envolvidos/as com o que foi desenvolvido. Elas, no entanto, lamentaram que dos 25 meninos e 22 meninas que frequentam as duas turmas de $5^{\circ}$ ano, apenas 25 compareceram naquele dia, pois quase metade deles/as não teve autorização dos/as responsáveis para participar da atividade. Com isso, afirmamos que algumas famílias acabam dificultando o trabalho com as questões de gênero e sexualidade nas escolas. Além do que, elas parecem não se dar conta de que a educação acontece em diferentes meios, como a televisão, os jornais, a internet, entre tantos outros meios que poderiam aqui ser citados. Parecem acreditar que a educação se restringe ao espaço escolar. Assim, se aí não se falar de sexualidade, crianças e jovens que por ela circulam não se interessarão por essa questão. De acordo com Louro (2000, p. 55-56):

\begin{abstract}
A sexualidade que "entra" na escola parece estar sitiada pela doença, pela violência e pela morte. São evidentes as dificuldades de educadoras e educadores, mães e pais, em associar a sexualidade ao prazer e à vida. Parece mais fácil exercer uma função de sentinela, sempre atenta à ameaça dos perigos, dos abusos ou dos problemas. São os possíveis riscos e danos que fornecem a pauta para as aulas de educação sexual. [...] travadas por estes limites, muitas das inquietações e dúvidas que mobilizam as crianças e os jovens deixam de ser expressas e só podem ser contempladas no interior dos seus próprios grupos. As dificuldades dos adultos em lidar com a sua própria sexualidade acabam por produzir uma muralha de constrangimento e de omissão.
\end{abstract}

Ademais, por intermédio dos exemplos aqui trazidos é possível perceber que existe dentro dos espaços escolares certa vigilância das condutas de seus alunos e alunas. A partir de visões pautadas nas diferenças anatômicas, professores/as direcionam os/as alunos/as para a construção de um comportamento aceito pela sociedade como sendo próprio para homens e mulheres. Essa atitude dos/as professores/as, mesmo que não intencional, acaba afirmando as desigualdades de gênero e sexualidade dentro da escola. A respeito da importância que a escola tem na construção das identidades dos sujeitos e na demarcação das diferenças, Meyer e Soares (2004, p. 8) afirmam que:

Desde sua constituição, a escola é marcada por diferenças e está implicada, também, com a produção dessas diferenças. 
Embora não seja possível atribuir a ela toda a responsabilidade pela construção das identidades sociais, ela continua sendo para crianças e jovens um local importante de vivências cotidianas específicas e, ao mesmo tempo, plurais.

Nessa mesma direção, Álvarez-Uría e Varela (2009) afirmam que a escola não produz as desigualdades (sejam elas de sexualidade, de gênero, de raça ou de classe, por exemplo), mas - muitas vezes - legitima-as à medida que reitera no seu interior normas postas em circulação na sociedade. Essa reiteração ocorre a partir dos comportamentos e falas de todos/as aqueles/as que por ela circulam, ou seja, professores/as, gestores/as, funcionários/as, alunos/as, responsáveis, entre outros/as.

É importante destacar a relevância do posicionamento da professora diante do comportamento de Roger, já que ela enfatizou não somente que não gostava, mas que não queria que ele chamasse o colega por apelidos depreciativos. Posicionamentos como esses, certamente, contribuem positivamente na formação de alunos e alunas no sentido de minimizar preconceitos e discriminações que ainda estão presentes nas escolas.

Mesmo que pequenos avanços venham ocorrendo no sentido de minimizar desigualdades de gênero e sexualidade, ainda há desrespeito por parte de crianças, jovens e adultos que circulam pelos espaços escolares em relação a sujeitos que não se vinculam à sexualidade heterossexual, bem como a mulheres. Com o propósito de diminuir preconceitos e discriminações é que algumas iniciativas têm sido pensadas, porém sua implementação tem sido dificultada e até mesmo suspensa.

A exemplo disso, pode ser citado o Programa Brasil sem Homofobia que, como foi mencionado anteriormente, tinha como um de seus objetivos a distribuição do "Kit Escola sem Homofobia", que procurava incentivar o combate à violência e à discriminação contra sujeitos cuja orientação sexual não era a heterossexual.Por outro lado, tal fato pode ainda trazer à discussão a importância de problematizarmos a qualidade e a eficácia desses materiais, que são produzidos para distribuição nas escolas, além de nos fazer pensar em relação a estratégias políticas mais eficazes para tratar desses temas, ainda tão delicados.

É importante ressaltar que, à medida que a escola ainda é uma das mais importantes instâncias implicada na produção das diferenças e no combate às desigualdades, torna-se cada vez mais necessário tratar das temáticas de gênero e sexualidade em momentos de discussão e reflexão. Desse modo, a escola estaria dando conta daquilo que se convencionou, em alguns documentos legais, chamar de Temas Transversais.

Costa (2003), entretanto, faz uma crítica ao fato de temáticas interessantes para crianças e jovens serem nomeados de transversais. Segundo ela, a maioria dos 
currículos continua priorizando as matérias que têm o objetivo de preparar o sujeito para um mundo ocidental coerente. A esse respeito, a referida autora afirma que há em documentos legais:

[...] uma evidência da necessidade de discutir outras questões na escola, temas novos, problemas novos. E como é que se resolveu? Já que não se pode romper com a ordem disciplinar, incluem-se temas transversais. Aquilo que deveria ser central é transversal. Aquilo que é problema da juventude hoje - sexualidade, drogas, comunicação, sobrevivência, como viver neste mundo complexo? - se resolve nos temas transversais. (COSTA,2003, p. 45).

Indiscutivelmente é possível perceber que a escola passou por algumas modificações ao longo do tempo, mas ainda continua rígida em relação às disciplinas que são intocáveis no currículo, como, por exemplo: a Matemática, o Português, a Biologia e a Física. É preciso incluir novas temáticas para dar conta das dificuldades e das necessidades dejovens e crianças que sentem a falta desse espaço para discussões acerca das questões de gênero, sexualidade, preconceitos raciais e desigualdade de classe social.

A escola vem discutindo esses problemas com a inserção dos temas transversais em algumas matérias, mas é preciso um objetivo claro para que essas questões não fiquem em segundo plano no planejamento das aulas. $\mathrm{Na}$ escola estão todos os sujeitos que vão formar a pluralidade a que os/as educadores/as precisam atender de uma forma que não exclua ninguém do processo de formação. Dessa forma, a escola poderia criar possibilidades de diminuir os preconceitos entre os sujeitos que a compõem não só na comunidade escolar, mas na sociedade de modo geral.

\section{CONSIDERAÇÕES FINAIS}

Ao direcionarmos o olhar para os sistemas educacionais é importante refletir sobre as desigualdades entre homens, mulheres, homossexuais, heterossexuais, bissexuaisque as escolas ainda acabam reforçando nas suas práticas mediante regras, situações, comportamentos e discursos que fazem parte do cotidiano. As identidades que unem grupos, diferenciando-os de outros, não deveriam resultar em relações de exclusão, desigualdade, discriminação e preconceitos. Porém, não raro é justamente isso que acaba ocorrendo, em razão de que suas identidades, marcadas muitas vezes pelas diferenças, não são respeitadas e, nesse caso, é necessário entrar no espaço de luta pelo reconhecimento dos direitos de todos e todas, independentemente de sexo, gênero, raça, religião, etc. 
Salientamos, ainda, que as instituições escolares não se constituem em lugares neutros e democráticos. Ao contrário, são espaços nos quais se disputam, se aceitam, se rejeitam e se impõem significados e normas que reiteram determinadas formas de viver as feminilidades e as masculinidades e as sexualidades.

Por fim, considerando o que vem sendo exposto até aqui é que enfatizamos, mais uma vez, que se torna inadiável levar para o campo da educação reflexões e questionamentos acerca das temáticas que se articulam a gênero e sexualidades. Essa tarefa, no entanto, não é fácil, pois trabalhar conceitos, noções, construções e desconstruções leva tempo e demanda um esforço conjunto.

Como destacado, é fato que as questões de gênero e sexualidade ganharam relevância em políticas e legislações que se vinculam tanto ao campo da educação quanto a outros campos, especialmente nas últimas décadas. Isso, entretanto, não é garantia de mudanças em relação aos comportamentos preconceituosos e discriminatórios que ainda acontecem nas escolas (e em outros espaços culturais e sociais). Para que haja um trabalho efetivo nas escolas de Educação Básica, é preciso não somenteque as temáticas em questão sejam incluídas em documentos legais (pareceres, orientações e/ou legislações), mas que haja investimento em formações docentes(tanto iniciais quanto continuadas) que sejam articuladasa gênero e sexualidades, para que aconteça o desencadeamento de discussões e debates em torno delas.

Nota explicativa

${ }^{1}$ Por envolver seres humanos, tais pesquisas, que contam com auxílio financeiro do Conselho Nacional de Desenvolvimento Científico e Tecnológico (CNPq), foram submetidas para aprovação na Plataforma Brasil e aprovadas pelo Comitê de Ética das Universidades em que atuamos.

\section{REFERENCIAS}

ÁLVAREZ-URÍA, F.; VARELA, J. Sociología de las instituciones: bases sociales y culturales de la conducta. Madrid: Morata, 2009.

BECK, Dinah; GUIZZO, Bianca. Estudos Culturais e Estudos de Gênero: proposições e entrelaces às pesquisas educacionais. Holos, Natal, v. 4,n, 29, p. 172-182, jul./ ago. 2013.

BRASIL. Constituição. Constituição da República Federativa do Brasil. Brasília, DF: Senado, 1988.

BRASIL. Lei n. 9.394, de 20 de dezembro de 1996. Estabelece as diretrizes e bases da educação nacional. Diário Oficial da União, Brasília, DF, 23 dez. 1996. 
BRASIL.Lei n. 10.172, de 9 de janeiro de 2001. Aprova o Plano Nacional de Educação e dá outras providências. Diário Oficial da União, Brasília, DF, 10 jan. 2001.

BRASIL. Ministério da Educação. Conselho Nacional da Educação. Diretrizes Curriculares Nacionais Gerais para a Educação Básica. Brasília: DF, 2010.

BRASIL. Portaria do MEC n ${ }^{\circ} 1$ 1.015, de 21 de julho de 2011. Aprova o Programa Mulheres Mil. Diário Oficial da União, Brasília, DF, 21 jul. 2011.

BRASIL. Lei n. 13.005, de 25 de junho de 2014. Aprova o Plano Nacional de Educação e dá outras providências. Diário Oficial da União, Brasília, DF, 26 jun. 2014.

BUTLER, J. Cuerpos que importán: sobre los limites materiales y discursivos del sexo. Buenos Aires: Paidós, 2005.

COSTA, Marisa Vorraber. A escola tem futuro? Rio de Janeiro: DP\&A, 2003.

FELIPE, J.Gênero, sexualidade e a produção de pesquisas no campo da educação: possibilidades, limites e a formulação de políticas públicas.Pro-Posições, Campinas, v. 18, n.2 (53), p. 77-87, maio/ago. 2007.

LOURO, G. L. Currículo, gênero e sexualidade.Porto: Porto Editora, 2000.

LOURO, G. L. Heteronormatividade e homofobia.In: JUNQUEIRA, Rogério (Org.). Diversidade sexual na educação: problematizações sobre homofobia nas escolas. Brasília, DF: Ministério da Educação/Unesco, 2009.p. 85-94.

MEYER, D.;SOARES, R. Corpo, gênero e sexualidade nas práticas escolares: um início de reflexão. In:MEYER, D.; SOARES, R. (Org.).Corpo, Gênero e Sexualidade. Porto Alegre: Mediação, 2004, p. 5-16.

RODRIGUES, T. C.;ABRAMOWICZ, A. O debate contemporâneo sobre a diversidade e a diferença nas políticas e pesquisas em educação. Educação e Pesquisa, São Paulo, v. 39, n. 1., p.15-30, jan./mar. 2013.

WEEKS, J. O corpo e a sexualidade. In: LOURO, G. L. (Org.). O corpo educado: pedagogias da sexualidade. Belo Horizonte: Autêntica, 1999. p. 35-82.

Recebido em 22 de junho de 2016

Aceito em 06 de janeiro de 2016

Endereço para contato:

Avenida Senador Salgado Filho, 411/401, Centro, 93260-140, Esteio, Rio Grande do Sul; mail: bguizzo_1@hotmail.com 
